\title{
Post-structuralism, hypertext, and the World Wide Web
}

\author{
Luke Tredinnick
}

School of Information Management, London Metropolitan University, London, UK

\begin{abstract}
Purpose - The purpose of this paper is to explore the application of post-structuralist theory to understanding hypertext and the World Wide Web, and the challenge posed by digital information technology to the practices of the information profession.

Design/methodology/approach - The method adopted is that of a critical study.

Findings - The paper argues for the importance of post-structuralism for an understanding of the implications of digital information for the information management profession.

Originality/value - Focuses on an epistemological gap between the traditional practices of the information profession, and the structure of the World Wide Web.
\end{abstract}

Keywords Worldwide Web, Information management, Information profession

Paper type General review

\section{Introduction}

This paper explores the application of post-structuralism to understanding hypertext and the World Wide Web. It is argued that the hypertext and the Web were developed with an explicit rejection of the epistemological models applied to traditional approaches to managing information. This rejection mirrors the critique of post-enlightenment rationalism offered by the French post-structuralist tradition. Post-structuralism therefore offers a theoretical framework and critical vocabulary that can be adapted for understanding the structures of information on the Web.

Hypertext has its origins in a paper by Vannevar Bush in which the automated retrieval of conceptually related texts using in-text cross-referencing was first described in the form of a conceptual information retrieval model, the Memex machine (McKnight et al., 1991, p. 7; Woodhead, 1991, p. 5; see Bush, 1945). Bush cited "the artificiality of systems of indexing" as the key problem in effective information retrieval (1945). Hypertext itself was conceptualised by Ted Nelson, who acknowledged the influence of the Memex machine in his work (Naughton, 1999, p. 220; Gillies and Cailliau, 2000). Nelson developed the idea of hypertext into Xanadu, a projected global information system (see Nelson, 2000). He felt that the fundamental problem with indexing systems is not that they are bad, but that different people at different times require different approaches (Landow, 1997, pp. 74-5). He therefore conceptualised hypertext as a supplement to classification.

The World Wide Web itself arose from Enquire, a personal information retrieval system developed by Tim Berners-Lee, apparently not directly influenced by Nelson or Bush, although with conceptual similarities (Berners-Lee, 1999, p. 5). The Web was developed as an information management tool (Berners-Lee, 1990, 1999, p. 17-19), although its potential as a global information system was recognised by Berners-Lee

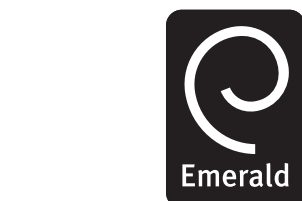

Received 24 March 2006 Revised 31 July 2006 Accepted 5 November 2006 西 
AP

59,2

170

(1991, 1999, p. 26) from the outset. Berners-Lee (1990, 1999, p. 22) believed that the formal hierarchical structures imposed on information management solutions inhibited information retrieval and sought to overcome this problem with textual networks connected by semantic and associative relationships.

The aspiration behind both hypertext and the Web was therefore in part an attempt to overcome perceived limitations in traditional approaches to managing information. These perceived limitations were identified with the imposition of formal classificatory structures on information. The perception was that these kinds of structures arbitrarily disassociated related information as a result of the application of a priori formal criteria. Hypertext and the Web, by exploiting loose associative relationships emerging from the texts of an information collection to create associative networks of information, was intended to overcome these perceived limitations.

A question arises as to why networks based on associative relationships should be seen as a more effective approach to organising information. Like Bush (1945), Berners-Lee (1999) conceived of the associative network as a model of the way in which the brain processes information, and therefore a better reflection of the cognitive processes involved in information retrieval. Ellis (1992, p. 56) has observed that this perhaps betrays a naïve understanding of cognitive processes. However, the role of network structures in the understanding of cognitive processes has become an increasingly important part of cognitive psychology (Gardner, 1987; Pinker, 1998). In particular, McCulloch and Pitts theory of neural interaction posits that the cognitive function resembles a network with weighted interactions (Gardner, 1987; Pinker, 1998; Waldrop, 1993). This has led to the mapping of cognitive processes through the use of graph theory (Pinker, 1998). This connection between weighted network structures and cognitive processes was highly influential on complexity theory, and the modelling of cognitive processes in information theory and neural networking (Waldrop, 1993; Lewin, 1993; Cilliers, 1998).

Berners-Lee focuses attention on the relationships between the elements of an information system, rather than on the elements themselves. Berners-Lee wrote of his inspiration for the Web:

In an extreme view the world can be thought of as only connections, nothing else. [...] I liked the idea that a piece of information is only defined by what it's related to, and how it's related.

There is really little else to meaning. The structure is everything (Berners-Lee, 1999, p. 14).

This description is very similar to the description of information processing arising out of complexity theory and neural networking. The theory of meaning implied here is not a classical mimetic model in which tokens stand in direct correspondence to the things for which they stand in place, but that of semiosis where meaning permeates, or emerges from the interactions implicit within the symbolic system itself (see Cilliers, 1998). Although Berners-Lee does not explicitly make the connection with complexity theory, the direction of his thinking highlighted in the quotation above does suggest the influence of complexity theory, widely popularised within the computing community of the time (see Tredinnick, 2006).

Cilliers $(1998,2005)$ has argued persuasively for the parallel between complexity theory and post-structuralist thinking. He has noted that both contain a rejection of post-enlightenment thought focussed on mimetic theories of representation and meaning. In their place, both erect theories of meaning posited on distributed 
representation that have parallels with cognitive models developed in cognitive psychology. This concentration on the distributed nature of representation exploits the power of network structures to define relationships between disparate nodes.

Two question arise: whether the perceived limitations of formal information organisation structures identified by Nelson and Berners-Lee do in fact limit the use of information in the way they imply, and, if they do, whether hypertext and the Web are able to overcome these limitations? It is in answer to these two questions that post-structuralism is able to clarify the rather nebulous set of ideas that contributed to the development of the Web. The critique offered by the structuralist, and later post-structuralist theorists, in many ways prefigures much of the current debate surrounding the influence of the Web on representation, and the growing dominance of network structures in information organisation and retrieval. There follows a brief overview of that critique, and the initial stages of a mapping of these issues onto the theory of the Web and hypertext.

\section{Structuralism and post-structuralism}

Post-structuralism originated in a reaction against the positivist outlook within the semiotic and structuralist critical tradition. Broadly speaking, semiotics is the study of signs and sign systems, and structuralism the application of semiotics to the study of cultural artefacts and cultural practices. Semiotics and structuralism largely derived from the linguistic analysis of Ferdinand de Saussure and the logic of Charles Sanders Peirce. Peirce identified a semiotic field of study, borrowing the term from Locke (Peirce, 1995, 1992; see Chandler, 2002, p. 6). By contrast, de Saussure (1966, p. 16) anticipated a "science of signs" named semiology, of which linguistics would be just one aspect. The two terms are generally used interchangeably. Eco (1976, p. 7) has written that semiotics "concerns everything that can be taken as a sign". Harland (1987, p. 2) has observed that semiotics and structuralism appropriate the scientific stance of objectivity and the scientific goal of truth, and Lotman (1990, pp. 17, 4) has argued that behind de Saussure is the culture of the nineteenth century with its faith in positivistic science and describes semiotics as a "scientific discipline". However, Bell et al. (2004) have termed semiotics a "so-called science", Rylance (1987, p. 112) "quasi-scientific", Turner (1990, p. 17) "not entirely scientific" and Harland (1987, p. 63) "more of a scientific aspiration than a realised science".

The analysis of de Saussure and Peirce was widely influential on critical and cultural theory. Culler (1975, p. 4) has suggested that this influence was based on two fundamental insights by later theorists: that social and cultural phenomena are themselves objects or events with meaning, and therefore signs; and that their meanings are not essential but defined by a network of internal and external relationships. The adoption of semiotic theory within cultural disciplines is therefore a product of its ability to reveal the mechanisms through which we make sense of the world (Turner, 1990, p. 14). Semiotics has as a result been applied to the study of diverse cultural practices (see Barthes, 1966 in Barthes, 1977, pp. 79-124, 1972; Chandler, 2002; Culler, 1975).

Within the English speaking tradition, Harland (1987, p. 4) has identified a focus on concrete application within semiotic practice that is "largely indifferent to matters of philosophy" and that fails to expel "certain assumptions deriving from Anglo-Saxon empiricism". Turner (1990, p. 22) notes that at the most elementary level, semiotics 
AP

59,2

172

supplies a terminology and conceptual frame for the analysis of symbolic systems and from this perspective the philosophy of structuralism becomes reduced to "method and technique" (Harland, 1987, p. 4). Within information science, semiotics has been recognised as a useful theoretical tool, although semiotic practice has been limited (Warner, 1990; Brier, 1996; Raber and Budd, 2003). Raber (2003, p. 225) has observed that "at first glance, de Saussure's work should be a central pillar of information science, yet the discipline has not embraced the implications". A theoretical framework for developing semiotics within the information disciplines has yet to emerge, however it is worth highlighting that semiotics is the one area of critical and cultural theory that has received serious attention within information science, and this is perhaps because its positivistic claims allied with the early scientific aspiration of Information Science.

Although the techniques of semiotic analysis continue to be utilised in a range of fields, de Saussure and Peirce invited more questions than structuralism itself could answer. Pure structuralism flourished only briefly (Rylance, 1987). In its wake, the post-structuralist movement attempted to tease out some of the uncomfortable implications of semiotics that structuralism had tended to gloss over. The leading writers of this movement, Roland Barthes, Michel Foucault, Julia Kristeva, Jaques Derrida and Gérard Genette, came out of the same French intellectual scene which had fermented structuralism. Post-structuralism is then both a continuation and critique of the structuralist tradition that preceded it; the "post-" reflects both its temporal and philosophical status. Despite the concentration of post-structuralism on text and texts, the study of information has largely failed to exploit post-structuralist theory (Day, 2005).

Roland Barthes was particularly important to this re-evaluation of semiotics after structuralism. By the late 1960s he had begun to turn away from his previous devotion to structuralist theory and explore some of the contradictions extant within the writing of de Saussure and Peirce. His essay From Work to Text (1971) represented a turning point not only in his own thought (Rylance, 1987, p. 112), but also in the structuralist movement. In it Barthes (1971) explored the transition of the literary object from a discrete artefact (the Work), to a node in a network of textual signification (the Text). He proposed that "a certain change has taken place in our conception of language and, consequently, of the literary work which owes at least its phenomenal existence to language". That change was the break that de Saussure had made between signs, and the things that they signify, or between words and their meaning. Barthes touched on a dichotomy between the physical manifestation of the literary work, and its signifying presence within the language system. The shift from Work to Text became for Barthes (1971) a symptom of an "unease in classification":

The work is a fragment of substance, occupying a part in the space of books (in a library, for example), the Text is a methodological field [...] It follows that the Text cannot stop (for example on a library shelf); its constitutive movement is that of cutting across (Barthes, 1971, p. 157).

Behind the literary text is the idea of the original individual creative act, an idea of originality that the diffuse nature of meaning in text destabilises. The work "functions as a general sign" - the work can be fitted into a discrete set of classification because its signification is discrete - it signifies the idea of itself. Thus in the Work is an assumption about the mimetic quality of language, the one-to-one correspondence between words and things, that was unsettled by de Saussure's negative value of the sign. As a result of that negative value, the Text "practices the infinite deferment of the 
signified” which Barthes calls "a playing” (Barthes, 1971, p. 158) in a similar sense that Derrida later exploited (see Derrida, 1978). The Work is seen as a singularity, but the metaphor of the Text is the network (Barthes, 1971, p. 160). While it was once understood that texts have determinate meaning that are essentially open to us, providing we pay enough attention, Barthes argues that the logical conclusion of semiotic theory is that the meaning of texts is always just out of view.

There is here a parallel with the kind of thinking about information, that influenced the origination of hypertext, and the Web outlined above. Barthes presents the work as bounded by the discrete signification imposed upon it, which severs its associative relationships with other works. This is a new way of looking at the function of text in culture which shifts the ontological status of text itself. Hypertext seeks to exploit the kinds of inter-relationship that Barthes suggests exists between texts, to allow individual texts to draw meaning from other texts through the use of associative connections. It encloses a tacit assumption that the full meaning of texts is drawn not simply from what they signify, but also from their place within the wider textual culture.

Foucault, another key theorist of the post-structuralist movement, is most well known for exploring the role of power within discourse. Discourse for Foucault is not just a way of speaking or writing, but the "whole 'mental set' and ideology which encloses the thinking of all members of society" (Barry, 2002, p. 176). In other words, discourse is a framework through which knowledge is transmitted and exploited, and, what is more, a framework regulated by power relations. Those power relationships are evident both between individuals, and more importantly between groups. Discourse therefore delimits not only what it is acceptable to say, but also what it is possible to say about given subjects at given times, and is therefore always the manifestation of power.

This central relationship in Foucault's work between power and knowledge is not, as it may appear, synonymous with Bacon's (1994, p. 43) assertion that "human knowledge and human power come to the same thing"; Bacon believed that knowledge was essentially empowering, where as Foucault argued that power regulates what comes to be constituted as knowledge (see Foucault, 1980). His archaeological method (see Foucault, 1972), to be distinguished from a traditional historical method that implied the narration of experiences from a position of power and privilege, was developed in a series of alternative histories: The Order of Things (Foucault, 1970), Madness and Civilization (Foucault, 1967), Discipline and Punish: the Birth of the Prison (Foucault, 1977) and The History of Sexuality (Foucault, 1979, 1984b, 1984c). These sought to undercut received historical understanding by highlighting the histories of the disempowered, or what he termed subjugated knowledge (Allen, 2000). Foucault has been influential in post-modernist theory (see Jenkings, 1991; Eagleton, 1996; Malpas, 2005), and certain strands of neo-Marxist critical theory (see Brannigan, 1998). However, Derrida (1978, pp. 36-76) criticised Foucault's deployment of dominant discursive practices in analysing the status of the supposedly silenced or subjugated.

Hayden White (1979, p. 81) has argued that Foucault rejected both logic and conventional analysis, however Harland (1987, p. 101) observes that "he rejects the notion of truth as a correspondence of ideas to things", or in other words the rejection of a mimetic model of representation. In The Order of Things Foucault (1970) argues that received structures of knowledge influence the way in which the world is understood. Elsewhere, Foucault (1980, pp. 131-2) located power in its application through control of discourse by essentially delimiting what it is possible to say. He denies the

\section{Post- structuralism, hypertext}

173 
AP

59,2

174

concreteness of the symbolic referent and rejects the notion that there is a "reality" which precedes discourse (White, 1979, p. 85).

Derrida is probably the most famous, and the most controversial of the post-structuralist theorists. His death in 2004 brought a mixture of lament, acclaim, perplexity and hostility. The announcement of his death by French President, Jaques Chirac, indicated the degree to which Derrida had been accepted into an intellectual and academic tradition of which he was always wary (Deutscher, 2005). However, an acerbic obituary in The New York Times, which accused Derrida of being an "abstruse theorist" (Kandell, 2004), demonstrates the antipathy that Derrida sometimes provoked. In the Times Higher, Simon Blackburn (2004) suggested that "Whether his intention was serious scholarship [...] his practice encouraged mainly mockery". More balanced obituaries appeared elsewhere, including that appearing in The Guardian which noted not only his influence on diverse fields such as architecture, theology, art, political theory, pedagogy, film, law and history, but also the "widespread and sometimes bitter" resistance to his writing (Attridge and Baldwin, 2004).

Derrida's general methodological approach was to subject texts to rigorous, piercing scrutiny, to uncover their hidden ambiguities, ambivalences and self-contradictions. This implies that Derrida applied nothing more than close reading, however his analysis turned on the self-negating qualities of language, which seem at the same time to denote meaning, and deny it. For Derrida, there was no "transcendental signified" in which meaning could ultimately be vested; meaning in language is deferred through endless chains of signification; we never arrive at a final signified because words are only meaningful through their difference with one another, and therefore there is no stable anchor to which meaning can be chained. Writing for Derrida was not a process of the denotation of objective meaning, but a play of meaning and signification. Derrida therefore sought out the points where texts exhibited the tension implied by a lack of signification, the points where texts spiral into self-contradiction, or get caught by their inability to articulate the clear distinctions that they assume.

Although Derrida did not systemise his ideas into a deconstructive method, his work was adopted and transformed into a method, particularly in the United States where the new criticism movement was beginning to grow old. Out of this emerged confusion between the writings of Derrida, and the writings of his followers, and a conflation of some of the tenets of new criticism and Derrida's own work. Derrida makes clear repeatedly that deconstruction is not to be considered a method to be applied to texts, but a quality of text itself. In a late roundtable discussion, he said:

Deconstruction is not a method or tool that you can apply to something from the outside [...] Deconstruction is something which happens inside; there is a deconstruction at work in Plato's texts, for instance (Derrida, 1997; cited by Deutscher, 2005, p. 6).

To read Derrida is therefore to grapple with two texts simultaneously: Derrida's own, and the text that he critiques. This results in an elusive rhetorical style which while succeeding in positioning his own writing on the edge of the process of signification he critiques (see Derrida, 2002), also renders his writing subject to endless reinterpretation. The kind of critical approach Derrida adopts has led to accusations of unrestrained relativism. However, Cilliers (1998, p. 22) has written that Derrida could only be termed relativistic by the "ignorant", Eagleton (2003, pp. 92-3) that Derrida seems "far too painstaking a reader" enthralled to an over-literal interpretation, and 
Norris (2002, pp. 156-78), that Derrida's painstaking careful analysis requires that we bring a similarly careful analysis to his own texts.

This concentration of post-structuralism on a set of themes including the transmission of meaning through language, the role of networks of signification, and the perpetuation of power has obvious parallels with the descriptions on hypertext and the World Wide Web explored above. The originators of hypertext and the Web share with post-structuralist theorists similar notions about the structure and workings of text, and, in particular, the network as the coordinating principle behind the transmission of meaning through texts. Post-structuralist theory challenges the assumption that organising structures can be imposed on information in a neutral and objective fashion. This is a similar mistrust to discrete set approaches to information organization and retrieval influencing the innovators of hypertext and the Web.

\section{Classification and rationalism}

A key motivation informing the development of Hypertext and the Web was the belief that formal information organisation structures impeded the potential use of information as a result of the way in which they poorly reflect the cognitive process at play in information retrieval. In The Order of Things, Foucault (1970, p. xvi) outlined his interest in the influence of conceptual schemas on naturalised classification. He cited a passage in Borges in which "a certain Chinese encyclopaedia" is said to categorise animals as:

a) belonging to the Emperor, b) embalmed, c) tame, d) suckling pigs, e) sirens, f) fabulous, g) stray dogs, $h$ ) included in the present classification, I) frenzied, $\mathrm{j}$ ) innumerable, $\mathrm{k}$ ) drawn with a very fine camelhair brush, l) et cetera, $m$ ) having just broken the water pitcher, $n$ ) that from a very long way off look like flies.

Foucault (1970, p. xvi) identified that "the exotic charm of another system, is the limitation of our own". The strangeness of the scheme reveals the limitation of our own conceptual frameworks. Foucault suggests that there are different legitimate ways of seeing the world that are reflected in the structural order we impose on phenomena, and that these differences depend on interpreting relationships between things in varying ways. Such classifications, therefore, are not derived from properties of things, but from ways of interpreting the relationships between them. Classification becomes here an extension of the play of semiotics. Foucault proceeded to suggest that our current understanding is limited by rationalism, which denies the legitimacy of certain kinds of associative relationships while asserting the greater legitimacy of others. He attempted to outline the analogical nature of pre-modern Western thought and contrast it with the inductive nature of post-enlightenment thought. This argument was influenced by Lévi-Strauss, who made a distinction between scientific and savage ways of thinking. Lévi-Strauss suggested that "scientific" modes of thought were fundamentally analytical, dividing nature into ever more precise categories. "Savage" modes of thought, on the other hand, were more holistic, seeking to understand nature in its entirety, and not just in its parts (Fiske, 1990, p. 115). It also mirrored an interest within medieval studies on the rhetorical mode of medieval writing, and in particular the extension of biblical exegesis into the practices of cultural production in other fields, typified by the groundbreaking work of Robertson (1962). Foucault, however, argued that the different structures of thought in the pre-modern and 
AP

59,2

176 post-enlightenment ages permeates the structures of language, and by extension the classifications that we apply to things.

The dilemma of subjectivity is, of course, inescapable in any act of classification, and Foucault follows in a long tradition questioning the basis of our knowledge about the phenomenal world, adopting a wholly relativist position. But Foucault's interest is less with the ontological status of aspects of the phenomenal world, and more with the function of the kinds of claims that are made about that status in the perpetuation of dominant modes of discourse and received interpretations. In other words, for Foucault it is not just that the rational basis of any form of classification can be questioned; rather his interest is in the function of the claims to authority that are manifest in the ways in which we legitimise certain ways of carving up phenomenal experience. The modern age relies more singularly on causal relationships in the formulation of phenomenal categories; the pre-modern age on analogical relationships. Both mark out the boundaries of an aspiration to power in the legitimisation of particular forms of knowledge, and the marginalisation of others.

The information profession relies heavily on the kinds of classificatory frameworks that Foucault critiques. These kinds of structures foreclose the possible meanings of information and to a degree impose particular meanings and interpretations. Foucault highlights the function of particular kinds of classifications in perpetuating certain dominant forms of knowledge. A question arises whether the particular kinds of classifications the information profession exploits act to perpetuate dominant forms of knowledge.

This issue of the influence of classification on the cultural process is not unacknowledged in the information profession. Wiegand (1998, pp. 183, 190), for example, in exploring the influences on the development of Dewey Decimal has focused on the role of the curriculum at Amherst College on Dewey's thinking, and notes that that curriculum represented "patriarchal White Western (and of course, Christian) civilization". He has suggested that "it is probably [...] fair to say that for the past century the scheme itself has quietly - almost invisibly - occupied an influential position as once of the forces sustaining the discursive formations of a Eurocentric patriarchy". This kind of influence is concealed by the apparent natural order of knowledge toward which the classification scheme strives, and the socio-cultural place of the library as a neutral gateway to knowledge. The theory of library classification in the age of Dewey made a claim to the objective status of the classification scheme as measured against the true order of knowledge (Hjørland, 2004). Dewey drew on Hegel and Bacon in providing the framework for his classification scheme, both of whom presented a teleological theory of knowledge (Graziano, 1959).

However, the point is not that particular classification schemes impose particular perspectives that delimit knowledge, and act to legitimize certain privileged forms of knowledge. The point is that any act of formal classification cannot avoid doing this. The very act of classification is to impose upon texts surrogate meanings that mediate the interpretations of texts. The information profession and the practice of organising books within libraries can from this perspective be seen as legitimising particular perspectives in culture. It is precisely the limitations for the use of knowledge implied by these kinds of issues that, as we have seen, motivated the innovators of hypertext and the Web to pursue alternative ways of organising and retrieving information, although those issues were not fully theorised and remained only partially articulated 
by Berners-Lee and Nelson. That is not to suggest that a concern with the perpetuation of power through dominant discourse was behind the Web, but rather recognition that particular ways of ordering information pose particular limitations which disrupted the full exploitation of information.

In balance with these limitations of classifications is the pragmatic aim to best organise information and knowledge for the purposes of information retrieval. Foucault's critique draws us towards a form of relativism in which all ways of organising information become equal, and concern with the utility of the classification scheme is marginalised. However, recognising the ways in which received knowledge can come to be inculcated into the structures of information is not necessarily the first step in rejecting all forms of information organisation, but a necessary first step in seeking ways of offsetting this influence while still aspiring to useful information organisation for the purposes of retrieval.

\section{Classification and structures of knowledge}

Subject classification acts to mediate the experience of the text. Particular texts are associated together, and certain aspects of the meanings of those texts valorised into a subject relationship; this by its very nature functions to foreclose the text and provide a final signification (if provisionally so). In other words, classification seeks to define the subject matter of particular texts, and in the process mediates the way in which those texts are subsequently encountered and read.

But subject classification is just the most obvious way in which attempts to organise information by formal means impose limits on the uses that can be made of information. The library and information profession makes use of a wide range of apparatus for mediating the experience of texts. The catalogue surrogate, for example, seeks to crystallize the essence of texts in sets of stable qualities. These qualities can themselves be seen as a way of stabilising meaning, or of reducing what Derrida (1978) termed the play of text. The particular qualities of texts that are valorised through bibliographic description centre on quasi-objective characteristics of text, such as author, subject matter, publisher, and so on, that all act to foreclose associative relationships between different texts. This unavoidably imposes certain conceptual frameworks that mediate understanding and interpretation. Bibliographic details, such as the title, presuppose an innate textual unity (Wolfreys, 1998) and act to direct interpretation (see Genette, 1997; Kristeva, 1980; Wolfreys, 1998).

These same qualities of text intrinsic to bibliographic extraction were described by Genette as the paratext, consisting of peritextual and epitextual components, or the textual scaffolding alongside, and outside the text. Gennette noted how texts rarely come without textual scaffolding that direct interpretation. Such scaffolding might include prefaces, title pages, the cover blurb, publisher's descriptions, and so on. According to Genette (1997), paratexts of this kind impose on the meaning of texts and are in part a mechanism for directing interpretation. They focus on particular qualities of the text, and act to define the meaning of the text, so that the experience of the text is mediated by a pre-apprehension of that meaning. The bibliographic description can also be thought of as a kind of paratext acting to direct interpretation.

The particular qualities isolated in the bibliographic description may appear to have no discernable impact on the apprehension of the meaning of the text they describe. However, these qualities were isolated as a result of the development of print as the 
AP

59,2

178 dominant form of textual representation, and reflect a particular assertion about the ontological status of texts. This is relatively clear in many cases; concepts such as publisher, place of publication, and date of publication have little relevance to the age prior to print when textual reproduction occurred through an ad hoc provision of formal and information provision, with hand-to-hand distribution, and personal copying playing a very significant role in the dissemination of texts (see Clanchy, 1993; Justice, 1996). Steinberg (1974) has traced the development of the title page out of the codex in early printed works, and the growing importance of bibliographic information as a result of the commercialisation of literary production. It is less obvious, although just as true, that other aspects of bibliographic description, such as the titles of works, and the compositions of works also resulted from the stabilising effects of print. The stabilising effect of print on titles has acted to strengthen the notion of the discrete signification of the textual work. Titles can be seen as a means of branding books, and of claiming of them a particular signification (see Genette, 1997).

This process extends as far as the concept of authorship. The modern association of authorship with an original creative act largely developed after the introduction of print. The medieval use of the term author tends to refer to the authority behind the text, and the relationship between authority and authorship was much more explicit. That does not mean that texts did not have writers, as such, but that the process of composition was not valorised in an individual creative act (Burrow, 1982). The skill more prised in composition was not originality, but the skilful reuse of authoritative sources of one kind or another. Thus, much medieval literature is composite in nature, and the source of texts was not as clearly associated with an original creative act as in the modern age. Scribes had an important role not just in copying texts, but also in editing, compiling, interpreting, glossing, censoring, translating and ultimately transforming the meaning of texts in a wide variety of ways (Burrow, 1982). The concepts of intellectual property and plagiarism that developed as a way of securing the economic exploitation of texts were completely unrecognised; once "published" the potential for asserting continuing control over the structure or context or texts was extremely limited.

The function of the modern concept of the author has draw specific comment from many of the key figures in the post-structuralist movement. Foucault (1984a) points out that the modern concept of the author is a post-enlightenment creation. Genette (1997) discusses the peritextual function of the author. Barthes, 1968 (in Barthes, 1977, pp. 142-8) argues that to give a text an author is to impose a limit on it, and attempt to provide it with a final signified value. Indeed, Foucault argues that the author really identifies an editorial function; that it works to enclose texts, to enclose relationships between texts, and to legitimise texts within discourse. The author is not intrinsic to the text, but imposed upon it in order to regularise discourse and knowledge. He argues that some discourses are endowed with an "authorial function" while others are deprived of it, and that this distinction having changed over time maps the application of power within discourse. The thrust of the post-structuralist critique of the author is that the identification of authorship itself acts as a means of asserting authority and control over text.

Two points are worth recognising: firstly, that the elements of bibliographic description can be understood to function to direct the interpretation of particular works by highlighting particular associations with other works, and by isolating particular qualities of significance, such as author, title, publisher and date of 
publication. Secondly, bibliographic description, by asserting a form of essentialism which focuses on the essential qualities of a work in which all copies partake to varying degrees, also asserts a particular understanding of the status of text. These kinds of structures can all be seen as mechanisms for closing down the play of the text, and means of isolating preferred interpretations. The bibliographic description and subject classification furnish a text with a final signified.

This attempt to impose a final signification through the identification and recording of formal bibliographic description downplays the degree to which the meaning of texts and the relationship between texts is constantly under re-interpretation. Kristeva (1980) described the text as a site of constant cultural production, meaning that the impression given that the meaning of texts is stable, and their place within culture settled, is an illusion of the mechanisms which within print culture seek to stabilise the apprehension of texts. What Barthes (1971) called the "constitutive movement [. . . of cutting across" is bounded by the mediation of bibliographic description, and the printing conventions from which the categories of bibliographic description arise. Text itself, which tended to be a constantly mutable medium in the age prior to print, has become a medium which allows the crystallisation of authoritative versions of individual texts.

It is worth noting in the light of this the difficulty in achieving bibliographic control over the Web. Torok (2003, pp. 203-4) has written in this context that "the dream of universal bibliographic control seems quite remote" in a Web that "consists of a vast unchecked sea" containing a "proliferation of document formats" that amount to "a large body of knowledge needing organising". However, Torok also notes that the Web is largely self-organising; and this indeed is precisely the point. The lack of bibliographic control is in essence a lack of centralised control; it reflects a shift in the control of text and information away from the major loci of the publishing age: publishers, governments, universities and other similar organisations. Organising information on the Web has become less a matter of defining what it is and what it is about, and more a matter of defining its relationship with other bits of information regardless of these formal qualities. The Web represents a turning away from final signification of textual works.

\section{The intertextual}

But that does not mean that the "cutting across" which Barthes describes ceases entirely in the printed text, but rather than our apprehension of it is suppressed. Derrida's (1976) aphorism that "there is nothing outside the text" is frequently interpreted in the light of New Criticism that considerations external to the text, such as authorial intention, are to be discounted. However, Derrida (1988) later clarified that there is nothing outside of context: that there is no such thing as unmediated experience as founded on a metaphysical subject/object binary dualism. Such boundaries and thresholds as are imposed on texts are artificial attempts to delimit meaning. Foucault (1972, p. 25) similarly writes that "the frontiers of a book are never clear cut". For Derrida (1978, pp. 351-378), "meaning is endlessly deferred"; he denies the possibility of a "transcendental signified" (Derrida, 2002, pp. 15-31) in which meaning can ultimately be vested. Thus, for Derrida, interpretation becomes about the play of language, rather than pinning down meaning. Barthes (1968, p. 147, in Barthes, 1977, pp. 142-8) makes a similar point that "Writing ceaselessly posits meaning ceaselessly to evaporate it, carrying out a systematic exemption of meaning". Barthes 
AP

59,2

180
(1971) noted that the Work as a material object can be treated as a sign with an iconic relationship with the semantic meaning of the text from which it is comprised.

From a post-structuralist perspective texts find meaning in their relationship with and difference from other texts, and the meaning of any text is diffused across this network of inter-related texts. Thus Foucault (1972, p. 25) argues that the book "is caught up in a system of references to other books, other texts, other sentences: it is a node within a network. From this perspective, traditional information management practices such as classification and cataloguing become attempts to limit this native intertextuality, to impose what Derrida termed a transcendental signified upon the textual work, and to delimit and stabilise the meaning of the text. This play of language which post-structuralism emphasises, where determinant meaning is never invested in individual texts but dispersed between texts, has become known as intertextuality, which Culler (1981, p. 114) identifies as the designation of a text's "participation in the discursive space of culture".

The intertextuality of text derives in part from the associations that texts form between themselves by being related in some way, and in part associations that links texts due to the context in which those texts are discovered. Contexts may include paratextual scaffolding (Genette, 1997), but also the place of texts within collections by which means they become associated. Beightol (1986, pp. 94-5), for example, describes "the intertextuality that obtains between the primary texts of documents that, by virtue of having been assigned to the same class in the same classification system, are intertextually linked" and notes that "a single document may be found to partake of different intertextual relationships when it is classified by different classification systems".

As meaning is diffused on intertextual and connotative relationships, the precise value of those intertextual connotations is dependent on the contextual arrangement or retrieval of texts (see Kristeva, 1980). How texts are read depends partly on the contexts in which they are encountered, or by where, in Barthes' (1971) sense, their works do stop on the shelf. Information management practices of classification and bibliographic description tend to constrain intertextual relationships, and constrain the contexts in which texts are encountered. By doing so, they perhaps impinge on the meaning of those texts. Under these conditions, such acts become effective interpretations in their own right, interpretations imposed on information by the information management profession. As Foucault's analysis suggests, it is very difficult to see how, if these practices fail to acknowledge the processes at work, they can avoid becoming mechanisms for the perpetuation of dominant ideas.

This description of interetextuality is also, of course, a description of hypertext; Berners-Lee (1999) made this explicit in his discussion of the epistemological basis of the Web, and Nelson described a docuverse in which "any user should be able to follow origins and links of material across boundaries of documents, servers, networks, and individual implementations" (cited by Naughton, 1999, p. 233). The action of hypertext and the World Wide Web as described by Nelson and Berners-Lee is precisely about breaking down the boundaries of the text, and making connections between texts that would not otherwise be possible. Hypertext and the Web therefore enclose a tacit rejection of the print tradition, and a promotion of the "cutting across" described by Barthes. 
Post-structuralism and the World Wide Web

The question that remains to be addressed is whether digital information in the model of hypertext and the Web represent a new paradigm for understanding and organising information, or a continuation by other means of an existing paradigm. It is clear that there are many parallels between the aspirations informing the creation of hypertext and the Web, and the critique of rationalism offered by post-structuralism. It is not, however, clear that these aspirations have been realised in the model of hypertext and the Web that resulted from the work of Nelson and Berners-Lee, among others. Although it is probably too early in the development of the Web to resolve this question, we can at least note some pointers that help to clarify this relationship.

Hypertext is conceptualised as non-linear text with inter-textual linking through embedded cross-references. Neither of these elements are intrinsically novel (see McKnight et al., 1991, pp. 15-38). The use of in-text cross-referencing predates hypertext. Medieval manuscripts were frequently glossed with commentaries and references to other texts (see Clanchy, 1993). In the printing age, referencing and footnoting have become a normalised method of highlighting the intertextual co-dependence of texts. By highlighting non-linearity as a distinctive feature of hypertext, we tacitly imply that printed texts are understood to be rigidly sequential. This is questionable. Non-linearity has been a feature of certain texts throughout the literary age. Examples include dictionaries, bestiaries and encyclopaedias. More than one commentator has observed the way in which these forms of literature tend to defer meaning by referencing other parts of themselves (e.g. Barthes, 1968, in Barthes, 1977, pp. 142-8). However, even "linear" texts are open to be read non-sequentially. Textual apparatus such as indices and contents pages point out this possibility. Linearity or lack of it largely proves to be a false criterion of distinction.

Hypertext differs, then, not in these characteristics, but in automating the retrieval of conceptually related texts, through what McKnight et al. $(1991$, p. 3) describe as "machine supported" links. Through this automation, the irreducible potential to combine and re-combine texts within new contexts is promoted. This challenges the stability and fixedness of the meaning of individual texts because it privileges intertextual relationships that impose on that meaning. The balance between disparate texts is upset, and the prominence of the other or external promoted. Text becomes re-conceptualised as a network of deferred meaning. It is in this incorporation of intertextual values, values that allow individual texts to become the locus of meaning drawn from disparate nodes, to become the site of the constant production of meanings, and to defer the attribution of absolute meaning, that any wider paradigm shift is likely to be centred.

However, it cannot go without comment that the very structures that Berners-Lee was seeking to avoid have tended to proliferate on the Web. Berners-Lee saw hierarchical sets as problematic, largely because of the possibility of related information being disassociated by virtue of the structure of the classification used. However, hierarchical structures have tended to proliferate on the Web. This is offset by widespread use of hyperlinks to cut across these kinds of structures, but predominantly websites do not reflect a network-structure, but a semi-networked hierarchical tree. It should also be noted that the first decade of web development largely followed a publishing model of information dissemination, in which control over information was asserted through the centralisation of information creation. In this light, hypertext and the Web cannot be seen to represent a new paradigm, but merely a new media.

\section{Post- \\ structuralism, hypertext}

181 
AP

59,2

182
This mixed picture can be seen as the product of two conflicting forces that may govern the development of the Web: the decentralising desire to cede to users control over texts, and the centralising desire to maintain with producers control over texts. To date, the latter tendency has been in ascendance, with an increasing commodification of the Web from its hobbyist and newsgroup origins (see Naughton, 1999).

However, this is not the whole story. In the first place, the characteristics of digital information itself perhaps pose a challenge to the way in which we regard information more generally. The ease of duplication of digital information that arises from its essential detachment from its material vehicle for most purposes to which that information is put encourages the rapid reuse, migration and transformation of information. This has made bibliographic control over digital information, and the Web in particular, intrinsically problematic. Bibliographic description became possible as a result of the stabilisation of text that arose out of printing. Steinberg has argued that:

What was epoch-making in Guttenberg's process was the possibility of editing, sub-editing and correcting a text which was (at least in theory) identical in every copy (Steinberg, 1974, p. 20).

Mechanical reproduction ensured that each copy of a single text would be for all intents and purposes identical. This allowed the qualities that all copies of a particular text shared to be abstracted and used as the basis of bibliographic description.

The mutability of digital information makes this isolation of essential characteristics of texts more problematic. Text becomes more explicitly the site of constant cultural production, as it is used and reused in different contexts, and transformed in the process. To some degree, this has set the Web at odds with existing intellectual property legislation. That is to say not only that the means of protecting intellectual property becomes more problematic as the means of extracting and transforming texts becomes easier, but also that the identification of the original creative act that underpins intellectual property becomes more problematic as text is subject to constant transformation. If we accept that the contexts within which information is discovered impinges on the meaning of information, then the rapid propagation of different contextual uses of the same information makes its absolute meaning more difficult to pin down, and more subject to mutability.

In the second case, the model of the Web that has dominated does not represent Berners-Lee's original conception. Berners-Lee (1999) conceptualised the Web as a more collaborative environment, where the browser would also act as the web-editor, and users would be engaged in the use and transformation of the resources they used. The divorcing of browser and web-editor imposed on the Web a publishing model of information transmission. Such asynchronous communications tools as were developed, such as forums and discussion groups, generally relied on the gradual accretion of contributions, rather than the transformation of the original text. This has had the effect of divorcing the act of creation, and the subsequent use of information. The reader and writer remained in a very different relationship to the text.

This failure to fully realise Berners-Lee's aspirations would be beside the point, if it were not that in the recent development of what have become known as Web 2.0 technologies can be seen a return to some of those original aspirations. The Wiki, in which users engage collaboratively in the authorship of texts is a particular case in point. Wiki content is unstable, changing in relation to the use that is made of it. The authenticity of Wiki content cannot be secured against an original creative act which 
stabilises an authoritative version of the text. The creative process at work on the Wiki is more akin to the transformation of manuscripts through the dissemination by hand-to-hand transmission and self-copying. It would be a mistake to push this analogy too far and claim a return to a previous textual mode, because in more important ways the Wiki and digital information is unlike the uses made of text in manuscript culture. However, they do point out a collaborative mode in knowledge creation that is increasingly finding a place on the Web, a mode which underplays the contributions of individual minds and focuses of the cultural process. The Wiki is not the only example of this mode; open source software relies in a similar way on collaboration. It is unsurprising, then, to see at the same time different approaches to the protection of intellectual property, which in the same way that the Web seeks to undermine traditional information management process, seeks to undermine copyright itself. Copyleft, for example, developed out of the GNU Public Licence Agreement, promotes the reuse of intellectual property, rather than its restriction. The boundaries between writing and reading are perhaps becoming less distinct in these mediums, such that to engage in reading becomes also a process of writing.

In the light of this, the question of whether hypertext and the Web represent new paradigms is perhaps superficial in its irresolvability. What is perhaps of more importance with regard to information management practice is the critique of traditional professional practices that is implied by the hypertext model. This does not, of course, mean that traditional information management practices no longer have a place in the digital age. But it does perhaps imply that there is a need to better understand how different approaches to organising information can act to disempower users, as well as to empower them.

\section{References}

Allen, G. (2000), Intertextuality, Routledge, London and New York, NY.

Attridge, D. and Baldwin, T. (2004), "Obituary: Jaques Derrida”, The Guardian, 11 October, p. 21.

Bacon, F. (1994), Novum Organum, with Other Parts of the Great Instauration, translated and edited by Peter Urback and John Gibson, Open Court, Chicago, IL and La Salle, TX.

Barry, P. (2002), Beginning Theory: An Introduction to Literary and Cultural Theory, Manchester University Press, Manchester and New York, NY.

Barthes, R. (Ed.) (1968), Image Music Text: Essays Selected and Translated by Stephen Heath, Fontana Press, London.

Barthes, R. (1971), "From work to text", in Barthes, R. (Ed.), Image Music Text: Essays Selected and Translated by Stephen Heath, Fontana Press, London.

Barthes, R. (1972), Mythologies; Selected and Translated from the French by Annette Lavers, Jonathan Cape, London.

Beightol, C. (1986), "Bibliographic classification theory and text linguistics: aboutness analysis, interetextuality and the cognitive act of classifying documents", Journal of Documentation, Vol. 42 No. 2, pp. 84-113.

Bell, D., Loader, B., Pleace, N. and Schuler, D. (2004), Cyperculture: The Key Concepts, Routledge, London.

Berners-Lee, T. (1990), Information Management: A Proposal, available at: www.w3.org/History/ 1989/proposal.html (accessed 1 June 2006).

\section{structuralism, hypertext}

183 
AP

59,2

184
Berners-Lee, T. (1991), "World Wide Web: a summary", email to: alt.hypertext, June 8, 1991, available at: http://groups.google.co.uk/groups?hl $=$ en\&lr $=\&$ frame $=$ right $\&$ th $=$ 684c55870fb47ede\&seekm = 6487\%40cernvax.cern.ch\#link1 (accessed 28 April 2005).

Berners-Lee, T. (1999), Weaving the Web: The Past, Present and Future of the World Wide Web by its Creator, Orion Business Press, London.

Blackburn, S. (2004), "Derrida may deserve some credit for trying, but less for succeeding", Times Higher Education Supplement, 12 November, p. 16.

Brannigan, J. (1998), New Historicism and Cultural Materialism, Macmillan Press, Basingstoke.

Brier, S. (1996), “Cybersemiotics: a new interdisciplinary development applied to the problems of knowledge organisation and document retrieval in information science", Journal of Documentation, Vol. 52 No. 3, pp. 296-344.

Burrow, J.A. (1982), Medieval Writers and Their Work: Middle English Literature and its Background 1100-1500, Oxford University Press, Oxford.

Bush, V. (1945), “As we may think”, Atlantic Monthly, Vol. 176 No. 1, pp. 101-8.

Chandler, D. (2002), Semiotics: The Basics, Routledge, London.

Cilliers, P. (1998), Complexity and Postmodernism: Understanding Complex Systems, Routledge, London and New York, NY.

Cilliers, P. (2005), “Complexity, deconstruction and relativism”, Culture, Theory \& Society, Vol. 22 No. 5, pp. 255-67.

Clanchy, M.T. (1993), From Memory to Written Record: England 1066-1307, Blackwell Publishing, Oxford.

Culler, J. (1975), Structuralist Poetics: Structuralism, Linguistics, and the Study of Literature, Cornell University Press, Ithaca, NY.

Culler, J. (1981), The Pursuit of Signs: Semiotics, Literature, Deconstruction, Routledge, London and New York, NY.

Day, R.E. (2005), "Poststructuralism and information studies", Annual Review of Information Science and Technology, Vol. 39, pp. 575-609.

de Saussure, F. (1966), Course in General Linguistics, Bally, C. and Sechehaye, A. (Eds), in collaboration with Riedlinger, A., translated with an Introduction by Baskin, W., McGraw-Hill, New York, NY.

Derrida, J. (1976), Of Grammatology, Gayatri Chakravorty Spivak (Trans.), Johns Hopkins University Press, Baltimore, MD and London.

Derrida, J. (1978), Writing and Difference, Allan Bass (Trans.), Routledge \& Kegan Paul, London and New York, NY.

Derrida, J. (1988), Limited Inc., Northwestern University Press, Evanston, IL.

Derrida, J. (1997), in Caputo, J.D. (Ed.), Deconstruction in a Nutshell, Fordham University Press, New York, NY.

Derrida, J. (2002), Positions, translated and annotated by Alan Bass, Continuum, London.

Deutscher, P. (2005), How to Read Derrida, Granta Books, London.

Eagleton, T. (1996), The Illusions of Post-Modernism, Blackwell Publishing, Oxford.

Eagleton, T. (2003), After Theory, Allen Lane, London.

Eco, U. (1976), A Theory of Semiotics, Indiana University Press, Bloomington, IN.

Ellis, D. (1992), "The physical and cognitive paradigms in information retrieval research", Journal of Documentation, Vol. 48 No. 1, pp. 45-64. 
Fiske, J. (1990), Introduction to Communications Studies, Routledge, London and New York, NY.

Foucault, M. (1967), Madness and Civilization: A History of Insanity in the Age of Reason, Howard, R. (Trans.), Tavistock Publications, London.

Foucault, M. (1970), The Order of Things: And Archaeology of the Human Sciences, Tavistock Publications, London.

Foucault, M. (1972), The Archaeology of Knowledge, Sheridan Smith, A.M. (Trans.), Tavistock Publications, London.

Foucault, M. (1977), Discipline and Punish: The Birth of a Prison, translated from the French by Sheridan, A., Allen Lane, London.

Foucault, M. (1979), The History of Sexuality, Vol. 1: Introduction, translated from the French by Hurley, R., Allen Lane, London.

Foucault, M. (1980), in Gordon, C. (Ed.), Power/Knowledge: Selected Interviews and Other Writings 1972-1977, Longman, London.

Foucault, M. (1984a), "What is an author", in Rabinow, P. (Ed.), The Foucault Reader, an Introduction to Foucault's Thought, Peregrine Books, Harmondsworth, pp. 51-75.

Foucault, M. (1984b), The History of Sexuality, Vol. 2: Introduction, translated from the French by Hurley, R., Penguin, Harmondsworth.

Foucault, M. (1984c), The History of Sexuality, Vol. 3: Introduction, translated from the French by Hurley, R., Penguin, Harmondsworth.

Gardner, H. (1987), The Mind's New Science: A History of the Cognitive Revolution; with an Epilogue Written by the Author, HarperCollins, London.

Gennette, G. (1997), Paratexts: Threasholds of Interpretation, Lewin, J.E. (Trans.), foreword by Macksey, R., Cambridge University Press, Cambridge.

Gillies, J. and Calliau, R. (2000), How the Web Was Born, Oxford University Press, Oxford.

Graziano, E.E. (1959), "Hegel's philosophy as basis for the Dewey Decimal Classification schedule", Libri, Vol. 9 No. 1, pp. 45-52.

Harland, R. (1987), Superstructuralism: The Philosophy of Structuralism and Post-Structuralism, Methuen, London.

Hjørland, B. (2004), "Arguments for philosophical realism in library and information science", Library Trends, Vol. 52 No. 3, pp. 487-506.

Jenkings, K. (1991), Re-Thinking History, Routledge, London.

Justice, S. (1996), Writing and Rebellion: England in 1381, University of California Press, London.

Kandell, J. (2004), “Jaques Derrida, abstruse theorist, dies in Paris at 74”, The New York Times, 10 October, p. 1.

Kristeve, J. (1980), Desire in Language: A Semiotic Approach to Literature and Art, Columbia University Press, New York, NY.

Landow, G.P. (1997), Hypertext 2.0: The Covergence of Contemporary Critical Theory and Technology, Johns Hopkins University Press, Baltimore, MD and London.

Lewin, R. (1993), Complexity: Life at the Edge of Chaos, J.M. Dent, London.

Lotman, Y.M. (1990), Universe of the Mind: A Semiotic Theory of Culture, Introduction by Umberto Eco, I.B., Tauris and Co, New York, NY.

McKnight, C., Dillon, A. and Richardson, J. (1991), Hypertext in Context, Cambridge University Press, Cambridge.

Malpas, S. (2005), The Postmodern, Routledge, London and New York, NY. 
Naughton, J. (1999), A Brief History of the Future: The Origins of the Internet, Weidenfeld \& Nicolson, London.

Nelson, T.H. (2000), Xanalogical Structure, Needed Now More than Ever: Parallel Documents, Deep Links to Content, Deep Versioning and Deep Re-Use, available at: http://xanadu.com. $\mathrm{au} / \mathrm{ted} / \mathrm{XUsurvey/xuDation.html} \mathrm{(accessed} 5$ May 2005).

Norris, C. (2002), Deconstruction: Theory and Practice, 3rd ed., Routledge, London and New York, NY.

Peirce, C.S. (1992), in Houser, N. and Kloesel, C. (Eds), The Essential Peirce: Selected Philosophical Writings, Vol. 1, Indiana University Press, Bloomington and Indianapolis, IN.

Peirce, C.S. (1995), Philosophical Writings of Peirce, Selected and Edited with an Introduction by Justus Buchler, Dover, New York, NY.

Pinker, S. (1998), How the Mind Works, Allen Lane, London.

Raber, D. (2003), The Problem of Information: and Introduction to Information Science, The Scarecrow Press, Lanham, MD and Oxford.

Raber, D. and Budd, J.M. (2003), "Information as sign: semiotics and information science”, Journal of Documentation, Vol. 59 No. 5, pp. 507-22.

Robertson, D.W. (1962), A Preface to Chancer: Studies in Medieval Perspectives, Oxford University Press, London.

Rylance, R. (Ed.) (1987), Debating Texts: A Reader in 20th Century Literary Theory and Practice, Open University Press, Milton Keynes.

Steinberg, S.H. (1974), Five Hundred Years of Printing, foreword by Warde, B., Penguin Books, Middlesex.

Torok, A.G. (2003), "Introduction to organizing the internet", Library Trends, Vol. 52 No. 2, pp. 203-8.

Tredinnick, L. (2006), Digital Information Contexts: Theoretical Approaches to Understanding Digital Information, Chandos Publishing, Oxford.

Turner, G. (1990), British Cultural Studies: An Introduction, Routledge, London and New York, NY.

Waldrop, M.M. (1993), Complexity: The Emerging Science at the Edge of Order and Chaos, Viking, London.

Warner, J. (1990), "Semiotics, information science, documents and computers", Journal of Documentation, Vol. 46 No. 1, pp. 16-32.

White, H. (1979), "Michel Foucault", in Sturrock, J. (Ed.), Structuralist and Since: from Levi-Strauss to Derrida, Oxford University Press, Oxford and New York, NY, pp. 81-115.

Wiegand, W.A. (1998), “The 'Amherst Method': the origins of the Dewey Decimal Classification System”, Libraries \& Culture, Vol. 33 No. 2, pp. 175-94.

Wolfreys, J. (1998), Deconstruction: Derrida, Macmillan Press, London.

Woodhead, N. (1991), Hypertext and Hypermedia: Theory and Applications, Sigma Press, Wilmslow.

\section{Corresponding author}

Luke Tredinnick can be contacted at: L.Tredinnick@londonmet.ac.uk

To purchase reprints of this article please e-mail: reprints@emeraldinsight.com Or visit our web site for further details: www.emeraldinsight.com/reprints 